\title{
Rheology and microstructure of experimentally deformed
}

\section{plagioclase suspensions}

\author{
D. Picard ${ }^{1, *}$, L. Arbaret ${ }^{1}$, M. Pichavant ${ }^{1}$, R. Champallier ${ }^{1}$ and P. Launeau ${ }^{2}$ \\ ${ }^{1}$ UMR (Unité Mixte de Recherche) CNRS (Centre National de la Recherche Scientifique) \\ 6113 Institut des Sciences de la Terre d’Orléans, 1a, rue de la Férollerie, 45071 Orléans,
}

France

${ }^{2}$ UMR CNRS 6112 Laboratoire de Planétologie et Géodynamique, Université de Nantes, rue de la Houssinière, 44322 Nantes, France

*E-mail: David.Picard@cnrs-orleans.fr

\section{ABSTRACT}

We present the result of the first deformation experiments at high-temperatures and highpressures on synthetic magmatic suspensions of strongly anisometric particles. The results highlight the interplay between the rheological response and the development of microstructures and they demonstrate the critical importance of the shape of crystals on the mechanical behaviour of magmas. Plagioclase suspensions with two crystal fractions $(0.38$ and 0.52 ) were deformed both in compression and in torsion in a Paterson apparatus. With increasing crystal fraction, the rheological behaviour of the magmatic suspension evolves from nearly steady-state flow to shear weakening, this change being correlated with a microstructural evolution from a pervasive strain to a strain partitioning fabric. Magmatic suspensions of plagioclase have viscosities approximately five orders of magnitude higher than suspensions of equivalent crystallinities made of isometric particles such as quartz.

Key-words: plagioclase fabrics, magma rheology, experimental deformation, strain partitioning. 


\section{INTRODUCTION}

During crystallization, magmas evolve from a viscous suspension, the rheological behaviour of which, mainly controlled by the liquid phase, can be modelled using the Einstein-Roscoe equation (Roscoe, 1952; Ishibashi and Sato, 2007), to an interconnected crystalline framework capable of transmitting deviatoric stresses (Petford, 2003) and which exhibits non-Newtonian behaviour (Caricchi et al., 2007; Lavallée et al., 2007; Champallier et al., 2008). This rheological evolution is essentially controlled by the crystal fraction and, for a given crystal fraction, by the strain rate (Caricchi et al., 2007; Mueller et al., 2010). However, the morphological characteristics of particles (length, width and aspect ratio) are suspected to have a major influence on the rheology of suspensions (Chong, 1971; Nicolas, 1992; Petford, 2009). Crystals with different aspect ratios have been considered in analogical and numerical modelling of the microstructural evolution of crystal-melt suspensions (Ildefonse et al., 1992; Saar et al., 2001). So far, high temperature and high pressure experimental deformation studies on magma rheology have focused on suspensions made of quasi isometric particles; corundum (Champallier et al., 2008), quartz (Caricchi et al., 2007), or natural partially crystallized suspensions (Caricchi et al., 2008; Cordonnier et al., 2009) have been investigated. Here, we present the first deformation experiments at high temperatures and pressures of synthetic suspensions of plagioclase, a representative strongly anisometric crystalline particle. With increasing cristallinity, a fundamental modification of the rheological behaviour is demonstrated and correlated with a dramatic evolution of the microstructure of the suspension. Our results stress the importance of the shape of crystals for natural magmatic flows.

\section{EXPERIMENTAL AND CHARACTERIZATION METHODS}

Plagioclase-bearing magmatic suspensions with crystal fractions $\left(\phi_{\mathrm{s}}\right)$ of 0.38 and 0.52 have been synthesized in an internally-heated pressure vessel for 7 days at $300 \mathrm{MPa}$ and 900 
and $800^{\circ} \mathrm{C}$, respectively. The resulting suspensions consist of homogeneously distributed euhedral plagioclase crystals embedded in a silicic glass containing some gas bubbles, indicating $\mathrm{H}_{2} \mathrm{O}$-saturated conditions (Fig. 1). Calculated glass $\mathrm{H}_{2} \mathrm{O}$ concentrations (Papale et al., 2006) are 7.1 and $6.7 \mathrm{wt} \%$, respectively for the $\phi_{\mathrm{s}}=0.38$ and 0.52 suspensions. Average surfacic crystal fractions of $0.38 \pm 0.01$ and $0.52 \pm 0.01$ were obtained on respectively 12 and 11 scanning electron microscopy (SEM) images. Plagioclases exhibit a tabular morphology (shape ratio $\mathrm{R} \sim 4$, Table 1 ) and are chemically homogeneous in the two suspensions.

The rheological measurements were performed with a Paterson apparatus (Paterson and Olgaard, 2000). The length / diameter of the sample deformed in compression $(\sim 1)$ is relatively small compared to ratios used in compression tests $(\geq 2$; Hawkes and Mellor, 1970). However, the low applied finite strain ensures a homogeneous no-slip deformation of the sample. The deformation experiments were performed at a confining pressure of 300 $\mathrm{MPa}$, temperatures of 900 and $800^{\circ} \mathrm{C}$ for $\phi_{\mathrm{s}}=0.38$ and 0.52 respectively (corresponding to the temperatures and pressures of synthesis of each suspension), and strain rates of $1 \times 10^{-5} \mathrm{~s}$ ${ }^{1}$ to $1 \times 10^{-3} \mathrm{~s}^{-1}$. Suspensions with $\phi_{\mathrm{s}}=0.52$ were deformed in torsion and with $\phi_{\mathrm{s}}=0.38$ in compression because the viscosity of the latter suspension was too low. To compare the apparent viscosities obtained in torsion and compression, compressive strain rates and stresses were converted to shear strain rates and stresses by using Eq. 39 and 40 from Paterson and Olgaard (2000). Three torsion experiments were performed (PP032, PP038, PP043), each at a different strain rate; however, for the no-slip compression experiment (PP070), a stepping strain rate procedure was applied (increase of the strain rate in a stepwise manner, once flow at constant stress is achieved).

The resulting microstructures were observed optically and with SEM on thin sections cut along the diameter, parallel to the length of the sample ([YZ] plane) in compression and normal to the radius of the core of the sample ([XZ] plane) in torsion. The long axis 
orientation $\alpha$ of the fabric was measured using the intercept method with Intercept2003 software (Launeau and Robin, 1996). The starting suspensions have a nearly isotropic fabric, with no preferred orientation as revealed by the random distribution of the long axis orientations on the rose diagram (Fig. 1). The 2D shape fabric obtained by the intercept method has been compared with the 3D crystallographic preferred orientation $(\mathrm{CPO})$ in one torsion experiment (PP043), measured using electron back-scattered diffraction (EBSD) technique (Heidelbach et al., 2000).

\section{RHEOLOGICAL MESUREMENTS AND MICROSTRUCTURAL OBSERVATIONS}

The chemical composition of the plagioclase does not change appreciably during the experiments (Table 1). The normative glass compositions are also constant and $\mathrm{H}_{2} \mathrm{O}$ concentrations are identical within error to those in the starting suspensions. Therefore, neither crystallization nor dissolution takes place during the deformation experiments.

In the compression experiment, for each applied strain rate, a linear increase of the stress with increasing strain characterizes the first step of deformation and corresponds to the relaxation time of the sample (Fig. 2A). The higher the strain rate, the higher the stress. The peak of the stress is reached at $\varepsilon \approx 0.5 \%$ for all applied strain rates, and it is followed by flow

at nearly constant stress. Two steps performed at the same high strain rates $\left(\dot{\varepsilon}=1 \times 10^{-3} \mathrm{~s}^{-1}\right)$ showed similar rheological behaviour which confirms the reproducibility of the experiments. The rheological response in the compression experiment is associated with the development of a pervasive fabric oriented at $\alpha=-3^{\circ}$ (Fig. 2B). No discrete structures, such as shear zones or bands, are observed

In the torsion experiments, a peak of the differential stress is reached at shear strains of $\gamma \approx 0.1$ (Fig. 2C). Iit is followed by a nearly steady state to $\gamma \approx 0.4$ and then by a decrease of the shear stress with strain, observed up to $\gamma=1.4$ (Fig. 2C), characteristic of strain weakening. This behaviour differs from those observed for quasi isometric particles where a 
stabilisation of stress with respect to strain occurs after the relaxation time (Caricchi et al., 2007; Champallier et al., 2008). This rheological behaviour is coupled with the development of a strong pervasive shape fabric of crystals at $\alpha=43^{\circ}$ with respect to the shear direction (Fig. 2D, zone 1). This fabric is crosscut by $40-\mu \mathrm{m}$-thick shear zones, spaced at $600 \mu \mathrm{m}$, oriented at $\alpha=-20^{\circ}$ and flanked by symmetrical shear gradients indicating a dextral sense of shear, synthetic to the bulk deformation (Fig. 2D, zone 2). According to Fernandez et al. (1983), a fabric orientation of $43^{\circ}$ is theoretically reached for $\gamma \sim 0.1-0.15$, which corresponds to the peak stress of our rheological curves. As this orientation is still observed at the final strain, we can assume that the development of the penetrative fabric is stopped at $\gamma \sim 0.15$ and the development of discrete parallel shear bands begins. The fabric inside the shear zone is oriented close to the bulk shear direction $\left(\alpha=-3^{\circ}\right)$ and not to the side of the shear band, regardless of the finite strain. This indicates that the fabric inside the shear band likely corresponds to a transtensional shear zone geometry in which the extensional flow apophyse is always parallel to the bulk simple shear. Plagioclase crystals inside and outside the shear zone have the same size, aspect ratio and chemical composition, and are identical to those in the starting suspension (Table 1).

The CPO of the plagioclases in the pervasive fabric (Fig. 2E) shows a maximum concentration of $\{010\}$ poles at $\sim 45^{\circ}$ counterclockwise with respect to the shear plane, and girdles of $\{001\}$ and $\{100\}$ at $\sim 60^{\circ}$ and $50^{\circ}$ clockwise. This indicates a dominantly planar fabric, with the trace of the $\{010\}$ plane in the $[\mathrm{XZ}]$ plane oriented near $45^{\circ}$ clockwise, similar to $\alpha\left(43^{\circ}\right)$. In the shear zone, plagioclases $\{010\}$ poles are oriented perpendicular to the bulk shear plane, as observed from the shape fabric. Both the $\{001\}$ and $\{100\}$ pole figures show a girdle parallel to the shear plane, with a maximum close to the bulk shear direction, defining a plano-linear crystallographic fabric.

\section{DISCUSSION}


The rheology of our experimental magmatic suspensions can be fitted by an Ostwald De Waele power-law equation (Ostwald, 1925) of the form, in compression:

$\dot{\varepsilon} \propto \sigma^{n}$

and in torsion:

$\dot{\gamma} \propto \tau^{n}$

where $n$ is the stress exponent. Values of $n$ close to 3 were measured for the two crystal fractions investigated. This suggests a non-Newtonian, shear-thinning rheological behaviour, already observed for quasi isometric and anisometric particles (Lavallée et al., 2007; Caricchi et al., 2007, 2008; Champallier et al., 2008, Cordonnier et al., 2009). The apparent viscosities of each suspension $\eta_{\text {app }}$ are calculated using the maximum stress $\sigma$ and $\tau$, and the strain rate $\dot{\varepsilon}$ and $\dot{\gamma}$, using either :

$\eta_{\text {app }}=\sigma / \dot{\varepsilon}$

in compression and

$\eta_{\text {app }}=\tau / \dot{\gamma}$

in torsion.

We introduce the relative viscosity $\eta_{r}$ defined as the ratio between the apparent viscosity $\eta_{a p p}$ (directly measured) and the viscosity of the interstitial melt $\eta_{0}$. Therefore, $\eta_{r}$ measures the influence of crystallinity parameters (e.g., crystal fraction and shape) on the rheology. The relative viscosities obtained in this study at different strain rates and crystal fractions are shown in Figure 3. At constant strain rate $\left(1 \times 10^{-4} \mathrm{~s}^{-1}\right)$, the relative viscosity increases by about $1 \log$ unit $\left(10^{5.65}\right.$ to $\left.10^{6.48}\right)$ when the crystal fraction increases from $\phi_{\mathrm{s}}=$ 0.38 to 0.52 . Furthermore, the strain weakening induces a decrease of the viscosity of about $0.25 \log$ unit for $\phi_{\mathrm{s}}=0.52$. 
Our relative viscosities can be compared with experimental results on suspensions of quasi isometric particles at strain rates similar to those of this study (Caricchi et al. 2007, Champallier et al. 2008; Fig. 3). Both types of suspensions are characterized by a stress exponent close to 3 : increasing the strain rate by $1 \log$ unit leads to a decrease of the relative viscosity by about $0.7 \pm 0.1 \log$ unit (Fig. 3). However, at given crystal fractions and strain rates, viscosities in this study are about $5 \log$ units higher than those obtained on suspensions of quasi isometric crystals (alumina, quartz). The Einstein-Roscoe equation, which fits quite well the rheological data for the quasi isometric suspensions, fails to reproduce our data by several orders of magnitude (Fig. 3). We emphasize that the size of crystals differs by about one order of magnitude between this and the experimental deformation studies above (Caricchi et al., 2007; Champallier et al., 2008). However, the size of crystals, although not systematically explored, is generally considered as a second-order parameter on suspension rheology (Mueller et al., 2010). Therefore, the critical parameter controlling the relative viscosities in the two groups of studies is the shape of crystals. Elongated particles are able to generate a crystal network and thus increase the viscosity of the suspension at low crystal fractions (Saar et al., 2001).

Our experimental microstructures are comparable to certain natural magmatic textures. At low crystal fractions $\left(\phi_{\mathrm{s}}<0.4\right)$, a pervasive fabric develops by crystal rotation and translation (Fernandez et al., 1983) and this leads to the stabilisation of the stress with increasing strain, as observed in our experiments (Fig. 2A). This corresponds to alignments and tiling of feldspar crystals in igneous rocks (Vernon, 2004). Such crystal fabrics are commonly used as kinematic indicators of early magmatic flow (Philpotts and Asher, 1994). With increasing the crystal fraction $\left(\phi_{\mathrm{s}} \sim 0.5\right)$, strain partitioning occurs, with the development of two associated fabrics (Vigneresse and Tikoff, 1999). These discrete structures, called "trachytic textures" in feldspar rich lava (Smith, 2002), are geometrically 
identified to $\mathrm{S} / \mathrm{C}^{\prime}$-like orientations and used in the field as shear sense indicators (Nicolas, 1992). They have been recently re-interpreted as asymmetric textural domains due to quasiviscous flow deformation on the flanks and bases of trachyte lava domes (Závada et al., 2009) and along conduit walls.

Our results can be directly applied to the evaluation of viscosity changes associated with the crystallization of microlites during ascent of andesitic magmas in volcanic conduits. This process yields groundmasses with as much as 50 vol\% microlites, essentially plagioclase (e.g., Burgisser et al., 2011). The change in relative viscosity associated with microlite crystallization can be estimated to be at least 5 orders of magnitude (Fig. 3). Assuming simple Poiseuille flow and a system free of gas bubbles, this implies a reduction of the magma ascent rate in the same proportions. This would promote the formation of a magma plug and the overpressurization of the underlying magma column, eventually leading to an explosive eruption.

\section{CONCLUSION}

Our high temperature high pressure experimental deformation tests provide the first documentation of the influence of high fractions of anisometric particles (plagioclase) on the rheology of synthetic magmatic suspensions. Upon increasing the crystal fraction, the magmatic suspension evolves from a nearly steady-state flow to a strain weakening behaviour, this change being correlated with a microstructural evolution from a pervasive to a strain-partitioning fabric. These results stress (1) the interplay between rheology and the development of microstructures and (2) the importance of the shape of crystals on the mechanical behaviour of the suspensions. Magmatic suspensions of plagioclase have viscosities approximately five orders of magnitude higher than suspensions of equivalent crystallinities made of isometric particles such as quartz. 


\section{ACKNOWLEDGEMENTS}

O. Rouer and A. Genty helped with the SEM and F. Heidelbach helped with the electron backscattered diffraction (EBSD) analyses. L. Peilleron provided useful technical assistance. This study was funded by the French programmes ACI Fabriques magmatiques (ACI JC3013) and ANR-EXPLANT (ANR-05-CATT-003). The European Union Research Infrastructure Transnational Access (\#131) programme supported the EBSD analyses at Bayreuth.

\section{REFERENCES CITED}

Burgisser, A., Arbaret, L., Druitt, T.H., and Giachetti, T., 2011, Pre-explosive conduit conditions of the 1997 Vulcanian explosions at Soufrière Hills Volcano, Montserrat: II. Overpressure and depth distributions: Journal of Volcanology and Geothermal Research, v. 199, p. 193-205.

Caricchi, L., Burlini, L., Ulmer, P., Gerya, T., Vassalli, M., and Papale, P., 2007, NonNewtonian rheology of crystal-bearing magmas and implications for magma ascent dynamics: Earth and Planetary Science Letters, v. 264, p. 402-419.

Caricchi, L., Giordano, D., Burlini, L., Ulmer, P., and Romano, C., 2008, Rheological properties of magma from the 1538 eruption of Monte Nuovo (Phlegrean Fields, Italy): An experimental study: Chemical Geology, v. 256, p. 158-171.

Champallier, R., Bystricky, M., and Arbaret. L., 2008, Experimental investigation of magma rheology at 300MPa: From pure hydrous melt to 75 vol. \% of crystals: Earth and Planetary Science Letters, v. 267, p. 571-583.

Chong, J.S., Christiansen, E.B., and Baer, A.D., 1971, Rheology of concentrated suspensions: Journal of Applied Polymer Science, v. 15, p. 2007-2021. 
Cordonnier, B., Hess, K.-H., Lavallee, Y., and Dingwell, D.B., 2009, Rheological properties of dome lavas: Case study of Unzen volcano: Earth and Planetary Science Letters, v. 279 , p. $263-272$.

Fernandez, A., Febesse, J.L., and Mezure, J.F., 1983, Theoretical and experimental study of fabrics developed by different shaped markers in two-dimensional simple shear: Bulletin de la Société Géologique de France, v. 3, p. 319-326.

Hawkes, I., and Mellor, M., 1970, Uniaxial testing in rockmechanics laboratories: Engineering Geology, v. 4, p. 177-285.

Heidelbach, F., Kunze, K., and Wenk, H.R., 2000, Texture analysis of a recrystallized quartzite using electron diffraction in the scanning electron microscope: Journal of Structural Geology, v. 22, p. 91-104.

Ildefonse, B., Launeau, P., Bouchez, J.L., and Fernandez, A., 1992, Effect of mechanical interactions on the development of shape preferred orientations : a two dimensional experimental approach : Journal of Structural Geology, v. 14, p. 73-83.

Ishibashi, H., and Sato, H., 2007, Viscosity measurements of subliquidus magmas: Alkali olivine basalt from the Higashi-Matsuura district, Southwest Japan: Journal of Volcanology and Geothermal Research, v. 160, p. 223-238.

Launeau, P., and Robin, P.Y.F., 1996, Fabric analysis using the intercept method: Tectonophysics, v. 267, p. 91-119.

Lavallée, Y., Hess, K.U., Cordonnier, B., and Dingwell, D.B., 2007, Non-Newtonian law for highly crystalline dome lavas: Geology, v. 35, no. 9, p. 843-846.

Mueller, S., Llewellin, E.W., and Mader, H.M., 2010, The rheology of suspensions of solid particles: Proceedings of the Royal Society, v. 466, p. 1201-1228.

Nicolas, A., 1992, Kinematics in magmatic rocks with special reference to gabbros: Journal of Petrology, v. 33, p. 891-915. 
Ostwald, W., 1925, Concerning the function rate of the viscosity of dispersion systems: IV: Kolloid-Zeitschrift, v. 36, p. 248-250.

Papale, P., Moretti, R., and Barbato, D., 2006, The compositionnal dependence of the saturation surface $\mathrm{H}_{2} \mathrm{O}+\mathrm{CO}_{2}$ fluids in silicate melts: Chemical Geology, v. 229, p. 7895.

Paterson, M.S., and Olgaard, D.L., 2000, Rock deformation tests to large shear strain in torsion: Journal of Structural Geology, v. 22, p. 1341-1358.

Petford, N., 2003, Rheology of granitic magmas during ascent and emplacement: Review of Earth and Planetary Science, v. 31, p. 399-427.

Petford, N., 2009, Which effective viscosity ?: Mineralogical Magazine, v. 73, p. 167-191.

Philpotts, A.R., and Asher, P.M., 1994, Magmatic flow-direction indicators in a giant diabase feeder dike, Connecticut: Geology, v. 22, p. 363-366.

Roscoe, R., 1952, The viscosity of suspensions of rigid spheres: British Journal of Applied Physics, v. 3, p. 267-269.

Saar, M.O., Manga, M., Cashman, K.V., and Fremouw, S., 2001, Numerical models of the onset of yield strength in crystal-melt suspensions: Earth and Planetary Science Letters, v. 187, p. 367-379.

Smith, J.V., 2002, Structural analysis of flow-related textures in lavas: Earth Science Review, v. 57, p. 279-297.

Vernon, R.H., 2004, A practical guide to rock microstructure, Cambridge University Press, $594 \mathrm{p}$.

Vigneresse, J.L., and Tikoff, B., 1999, Strain partitioning during partial melting and crystallizing felsic magmas: Tectonophysics, v. 312, p. 117-132. 
Závada, P,. Schulmann, K., Lexa, O., Hrouda, F., Haloda, J., and Týcova, P., 2009, The mechanism of flow and fabric development in mechanically anisotropic trachyte lava: Journal of Structural Geology, v. 31, p. 1295-1307.

\section{FIGURE CAPTIONS}

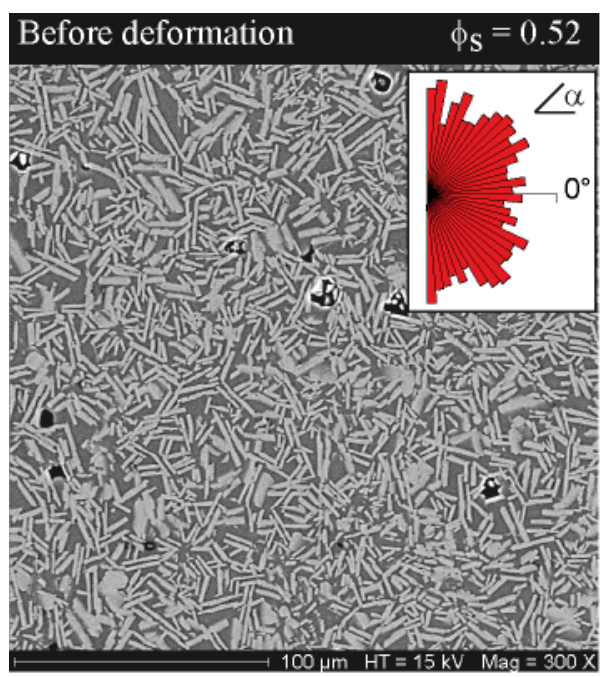

Figure 1. SEM microphotograph of a plagioclase bearing suspension before deformation with $\phi_{\mathrm{s}}=0.52$. Plagioclase in light grey, silicic glass in dark grey and gas bubbles in dark. The inset shows the local plagioclase fabric long axis orientations $(\alpha)$ displayed together on the rose diagram. Long axis orientations $\alpha$ are respectively positive and negative for an counterclockwise and a clockwise orientation. 


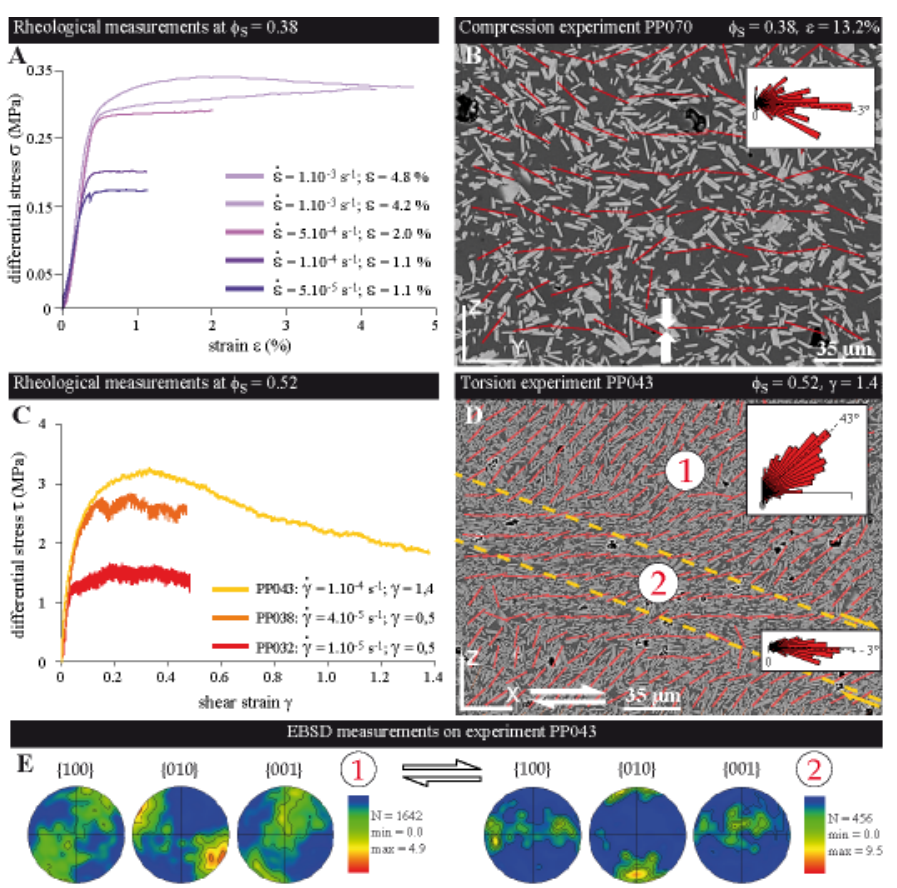

Figure 2. Rheology and microstructures of plagioclase-bearing suspensions deformed in compression (A, B) and in torsion (C-E). A: Rheological curve ( $\sigma$ vs. $\varepsilon$ ) for the same suspension PP070 $\left(\phi_{\mathrm{s}}=0.38\right)$ deformed in compression at different strain rates $(\dot{\varepsilon}$, stepping strain experiment). B: SEM microphotograph of PP070 sample. Plagioclase in light grey, silicic glass in dark grey and gas bubbles in dark. The long axes of the local (i.e. for each subwindow) crystal fabric are represented by red lines and displayed together in the rose diagram (inset). White arrows indicate the type of deformation. C: Rheological curves ( $\tau$ vs. $\gamma$ ) for 3 suspensions (PP032, PP038 and PP043) with $\phi_{\mathrm{s}}=0.52$ deformed in torsion, each with a different strain rate $(\dot{\gamma})$, as indicated. D: SEM microphotograph of PP043 sample. The rose diagrams of the local plagioclase fabric in the penetrative zone (zone 1) and in the shear zone (zone 2) are respectively shown in the upper and lower insets. E: Pole figures of the 3 plagioclase main crystallographic axes $(\{001\},\{010\}$ and $\{100\})$ are shown for the pervasive fabric (zone 1) and the shear zone (2) for sample PP043. 


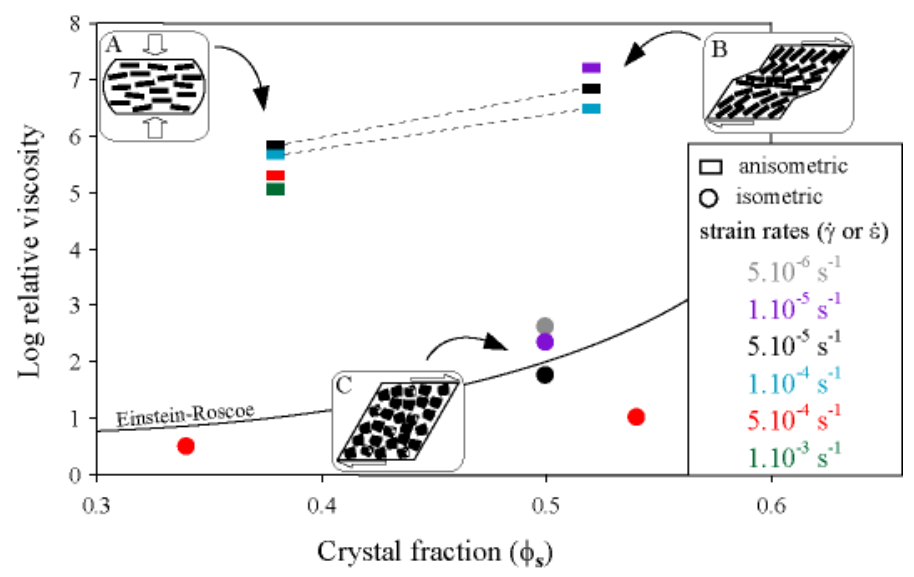

Figure 3. Relative viscosities of magmatic suspensions plotted as a function of the crystal fraction above $\phi_{\mathrm{s}}=0.3$. Data for anisometric crystals (plagioclase) from this study (rectangles) and for nearly isometric crystals (quartz, alumina) from Caricchi et al. (2007) and Champallier et al. (2008). Color coding relates experimental data points to applied strain rates. The errors are smaller than symbol sizes. The continuous line gives the relative viscosities calculated using the Einstein-Roscoe equation using $\eta_{0}=10^{4}$ Pa.s, an exponent (n) of 2.5 and $\phi_{\max }=0.62$. The three insets are interpretative sketches of the microstructures of the suspensions in three cases. A: anisometric crystals steady-state flow. B: anisometric crystals, strain weakening. C: quasi isometric crystals, steady-state flow.

TABLE 1. MORPHOLOGICAL AND CHEMICAL CHARACTERISTICS OF THE PLAGIOCLASE SUSPENSIONS

\begin{tabular}{|c|c|c|c|c|c|c|c|c|c|c|c|c|c|c|c|}
\hline \multirow[b]{2}{*}{$\phi_{\mathrm{s}}$} & & & & \multicolumn{8}{|c|}{ Plagioclase } & \multicolumn{4}{|c|}{ Glass } \\
\hline & & & & $a(\mu \mathrm{m})$ & $\sigma$ & $\mathrm{b}(\mu \mathrm{m})$ & $\sigma$ & $\mathrm{R}$ & $\sigma$ & An & $\sigma$ & Qtz & $\mathrm{Ab}$ & $\mathrm{An}$ & $\mathrm{H}_{2} \mathrm{O}$ (wt. \%) \\
\hline \multirow{2}{*}{0.38\{} & starting suspension & $\# 13$ & & 5.61 & 4.67 & 1.96 & 1.37 & 3.56 & 1.84 & 0.33 & 0.01 & 24.5 & 69.0 & 6.5 & 7.1 \\
\hline & deformed suspension & PP070 & & 6.56 & 4.88 & 2.10 & 1.8 & 3.67 & 1.75 & 0.34 & 0.01 & 24.0 & 69.0 & 7.0 & 7.1 \\
\hline \multirow{3}{*}{0.52\{} & starting suspension & \# 07 & & 6.19 & 5.23 & 1.82 & 1.85 & 4.05 & 1.96 & 0.29 & 0.01 & 28.0 & 66.5 & 5.5 & 6.7 \\
\hline & deformed suspension & 2043 & pervasive fabric & 6.40 & 3.26 & 1.84 & 1.01 & 3.75 & 1,67 & 0.27 & 0.01 & \multirow{2}{*}{26.5} & \multirow{2}{*}{68.0} & \multirow{2}{*}{5.5} & \multirow{2}{*}{6.7} \\
\hline & detuming suspension & 040 & shear zone & 6.16 & 3.34 & 1.54 & 0.58 & 4.08 & 1.75 & 0.29 & 0.01 & & & & \\
\hline
\end{tabular}

Note: $a$ is the length of the crystals, $b$ the width and $R$ the shape ratio, $R=\left(\sum_{0}^{i} a / b j\right) / i$ with $i=$ number of analysed crystals. $\sigma$ is the standard deviation. An=Atomic $\mathrm{Ca} /(\mathrm{Ca}+\mathrm{Na})$ of plagioclase crystals determined from electron microprobe analyses. $\mathrm{Qtz}, \mathrm{Ab}, \mathrm{An}=$ normative quartz, albite and anorthite contents of the glasses, calculated from electron microprobe analyses. $\mathrm{H}_{2} \mathrm{O}$ is the water concentration of the glass, calculated assuming water saturation using the model of Papale et al. (2006). 